\title{
Características de carcaça e qualidade da carne de bovinos de corte de quatro grupos genéticos terminados em confinamento
}

\author{
Saulo Malaguido Climaco${ }^{1}$, Edson Luis de Azambuja Ribeiro², Ivone Yurika Mizubuti², \\ Leandro das Dores Ferreira da Silva ${ }^{2}$, Marco Aurélio Alves de Freitas Barbosa ${ }^{2}$, Bruno \\ Mazzer de Oliveira Ramos ${ }^{1}$, Camila Constantino ${ }^{1}$
}

\footnotetext{
1 Programa de Pós-graduação em Ciência Animal, UEL.

2 Departamento de Zootecnia, UEL.
}

RESUMO - Este trabalho foi realizado com o objetivo de avaliar as características de carcaça e a qualidade da carne de animais puros das raças Tabapuã, Bonsmara e mestiços 1/2 Bonsmara $+1 / 2$ Nelore e mestiços $1 / 2$ Bonsmara $+1 / 4$ Red Angus + $1 / 4$ Nelore. Foram utilizados cinco bovinos castrados de cada grupo genético, com idade média de 22 meses e peso vivo de $394 \pm 21 \mathrm{~kg}$ ao início do experimento. A dieta, para todos os animais, continha silagem de cana-de-açúcar e ração comercial na proporção de 55\% e $45 \%$ (base seca), respectivamente, com 14,99\% de proteína bruta (PB) e 59,84\% de nutrientes totais digestíveis (NDT). Ao abate, não foram observadas diferenças no peso de carcaça fria nem nos pesos e percentuais dos cortes comerciais (traseiro, costilhar e dianteiro) entre os grupos genéticos. Os animais puros Bonsmara apresentaram maior área de olho-de-lombo, maior percentual de músculo e menor percentual de gordura na carcaça. Nos animais mestiços $1 / 2$ Bonsmara $+1 / 2$ Nelore, a espessura de gordura de cobertura (EGC) foi maior que os Bonsmara e Tabapuã, porém todos os grupos genéticos apresentaram EGC acima do mínimo (3 mm) exigido pelos frigoríficos. Não foi observada diferença na composição centesimal da carne entre os grupos genéticos. A carne dos animais Bonsmara e mestiços 1/2 Bonsmara $+1 / 2$ Nelore e $1 \frac{1}{2}$ Bonsmara $+1 / 4$ Red Angus $+1 / 4$ Nelore foi mais macia que a dos animais Tabapuã. O perfil de ácidos graxos no músculo longissimus dorsi não diferiu entre os grupos genéticos estudados. A carne dos animais Bonsmara e mestiços 1/2 Bonsmara $+1 \frac{1}{2}$ Nelore e $1 / 2$ Bonsmara $+1 / 4$ Red Angus + $1 / 4$ Nelore apresentou melhor qualidade se comparada à dos Tabapuã.

Palavras-chave: ácidos graxos, Bonsmara, cruzamento, gordura, maciez, Tabapuã

\section{Carcass characteristics and meat quality of four genetics groups of beef cattle finished in feedlot}

\begin{abstract}
The objective of this study was to evaluate carcass traits and meat quality of Tabapuã and Bonsmara purebred steers, and crossbred 1/2 Bonsmara $+1 / 2$ Nellore and 1/2 Bonsmara $+1 / 4$ Red Angus $+1 / 4$ Nellore steers. Five animals were used in each genetic group. The average age and weight at the beginning of the experiment were 22 months and $394 \pm 21 \mathrm{~kg}$. All animals received the same diet, which was composed of sugar cane silage and a commercial ration, in a ratio of 55 and $45 \%$ (dry matter basis), respectively, with 14.99 crude protein and 59.84\% total digestible nutrients. There were no differences between the genetic groups for cold carcass weight or percentages of commercial cuts (forequarter, hindquarter and sidequarter) at slaughter. Bonsmara steers presented the greatest ribeye area and percentage of muscle, and the lowest percentage of fat in the carcass. Crossbred 1 1 12 Bonsmara $+1 / 2$ Nellore animals presented greater back fat thickness (BFT) than Bonsmara and Tabapuã animals; however, all genetic groups presented BFT greater than the minimum $(3 \mathrm{~mm})$ required by the meat industry. There was no difference in the meat centesimal composition between genetic groups. Meat from Bonsmara, $1 / 2$ Bonsmara $+1 / 2$ Nellore and $1 / 2$ Bonsmara $+1 / 4$ Red Angus $+1 / 4$ Nellore presented greater tenderness than that from Tabapuã steers. The longissimus fat acid profile did not differ between the genetic groups studied. Meat from Bonsmara and crossbred $1 / 2$ Bonsmara $+1 / 2$ Nellore and $1 / 2$ Bonsmara $+1 / 4$ Red Angus $+1 / 4$ Nellore animals presented greater quality than that from Tabapuã steers.
\end{abstract}

Key Words: Bonsmara, crossbreeding, fat, fatty acids, Tabapua, tenderness

\section{Introdução}

A qualidade da carcaça e da carne de bovinos de corte é influenciada por vários fatores, entre eles, a genética, a alimentação, o sexo, a idade e o manejo pré-abate (Alves et al., 2005). A maciez é um dos principais atributos de qualidade da carne: é a característica organoléptica de maior influência na aceitabilidade pelos consumidores 
(Alves et al., 2005; Parmigiani \& Torres, 2009). A carne produzida no Brasil, principalmente a partir de animais zebuínos, é identificada como dura, pois os animais são terminados geralmente a pasto e atingem o peso de abate a maiores idades (Parmigiani \& Torres, 2009).

A menor maciez da carne dos animais mais velhos ocorre pelo maior número de ligações cruzadas termoestáveis do colágeno nos músculos (Hadlich et al., 2008). Outro fator que tem sido apontado como responsável pela menor maciez da carne de zebuínos é a diferença na ação das enzimas proteolíticas no período pós abate (Curi et al., 2009). Nos zebuínos, há maior atividade da calpastatina, inibidora da calpaína, principal responsável pelo amaciamento da carne (Hadlich et al., 2008).

Programas de melhoramento genético de gado de corte tem sido, tradicionalmente, focados no ganho de peso vivo. No entanto, ultimamente, em função da exigência em qualidade do produto pelo mercado consumidor, os programas de melhoramento tem aumentado a ênfase sobre as carcaterísticas de composição corporal (Faria et al., 2009). O uso de cruzamentos, incluindo raças taurinas, aumenta a probabilidade de se melhorar a maciez da carne e diminuir a idade ao abate (Alves et al., 2005; Parmigiani \& Torres, 2009).

É de interesse do consumidor que a carne apresente menores teores de lipídeos totais, ácidos graxos saturados e calorias, assim como maiores teores de ácidos graxos poliinsaturados, importantes na prevenção de doenças cardiovasculares. Todavia, a gordura, além de proteger as carcaças da ação do frio, é uma importante fonte de ácidos graxos essenciais e transportadora das vitaminas lipossolúveis, além de consistir em fonte de energia e isolamento para o corpo. Além disso, tem importante papel no desenvolvimento do sabor e do aroma da carne (Luchiari Filho, 2000), embora possam ocorrer variações significativas na composição lipídica total e entre ácidos graxos na carne de diferentes grupos genéticos de bovinos (Rossato et al., 2009).

O objetivo neste trabalho foi avaliar as características de carcaça e a qualidade da carne de bovinos das raças Bonsmara puros e mestiços e também Tabapuã.

\section{Material e Métodos}

O experimento foi conduzido na Fazenda Barbacena, município de São Pedro do Ivaí, região noroeste do estado do Paraná. O projeto de pesquisa foi aprovado pelo Comitê de Ética em Pesquisa com Animais da Universidade Estadual de Londrina.
Foram utilizados 20 bovinos, cinco de cada grupo genético (Bonsmara (B); $1 \frac{1}{2}$ Bonsmara + 1/2 Nelore (B1); $1 / 2$ Bonsmara $+1 / 4$ Red Angus + 1/4 Nelore (B2); e Tabapuã (T)), machos castrados, com idade média de 22 meses, peso vivo de $394 \pm 21$ kg e escore de condição corporal 2 ao início do confinamento. Os animais foram abatidos quando o grupo atingiu escore de condição corporal 3. Foi utilizada uma escala de escore de condição corporal que variava de 1 a 5 (Machado et al., 2008); em que: 1 = muito magros ou caquéticos (processos transversos e espinhosos e costelas bem visíveis; cauda totalmente inclusa dentro do coxal e íleos e ísquios expostos; atrofia muscular), 2 = magros (ossos bastante salientes, com certa proeminência dos processos dorsais e dos íleos e dos ísquios; costelas com pouca cobertura; processos transversos visíveis; cauda menos inclusa nos coxais), 3 = médio (cobertura muscular suave; processos dorsais pouco visíveis; costelas quase cobertas; processos transversos pouco aparentes), 4 = gordo (boa cobertura muscular, com alguma deposição de gordura na inserção da cauda; costelas e processos transversos completamente cobertos; regiões individuais do corpo ainda são bem definidas; partes angulares do esqueleto menos identificáveis), e 5 = muito gordo ou obeso (ângulos do corpo cobertos, incluindo as partes salientes do esqueleto, onde aparecem camadas de gordura; partes individuais do corpo difíceis de ser distinguidas e o animal tem aparência arredondada).

Os bovinos foram mantidos em confinamento durante todo o período experimental, e foram distribuídos aleatoriamente em baias cobertas. O período experimental total foi de 119 dias, com pesagens, após jejum de sólidos. Os animais B1 e Bonsmara foram abatidos após 100 dias de confinamento, os B2 após 106 dias, e os Tabapuã aos 119 dias.

$\mathrm{O}$ alimento foi fornecido duas vezes ao dia, às $8 \mathrm{~h}$ e às 17h30. A relação volumoso:concentrado na matéria seca da ração foi de 55:45. O volumoso utilizado foi a silagem de cana-de-açúcar e o concentrado uma ração comercial, constituída de farelo de trigo, melaço, milho grão, resíduo de soja, farelo de soja, ureia pecuária, calcário calcítico, múltiplo vitamínico, múltiplo mineral e sal comum. A quantidade de alimento fornecida aos animais foi ajustada para se obter em torno de $10 \%$ de sobras de alimento no cocho, a qual era pesada diariamente, pela manhã. A mistura do concentrado ao volumoso foi feita diariamente em vagão misturador (Tabela 1 ).

Diariamente, foram pesadas e colhidas amostras da dieta, que foram analisadas no Laboratório de Nutrição Animal da Universidade Estadual de Londrina. Foram 
Tabela 1 - Composição químico-bromatológica da dieta experimental

\begin{tabular}{lc}
\hline Composição da ração total & \% na matéria seca \\
\hline Matéria seca & 53,92 \\
Proteína bruta & 14,99 \\
Extrato etéreo & 1,40 \\
Matéria mineral & 6,54 \\
Extrato não-nitrogenado & 48,80 \\
Fibra em detergente neutro & 56,83 \\
Fibra em detergente ácido & 35,12 \\
Nutrientes digestíveis totais ${ }^{1}$ & 59,84 \\
\hline${ }^{1}$ Calculados de acordo com McDowell et al. (1974).
\end{tabular}

determinadas as porcentagens de matéria mineral, proteína bruta e extrato etéreo pelo método de Wendee, e fibra em detergente ácido e fibra em detergente neutro pelo método de Van Soest, conforme citado por Silva \& Queiroz (2002). O teor de nutrientes digestíveis totais (NDT) foi estimado de acordo com McDowell et al. (1974).

Na época do abate, os animais foram enviados para frigorífico comercial, onde foram insensibilizados por concussão cerebral, com pistola de dardo cativo, seguida por sangria pela secção das artérias carótidas e veias jugulares. Imediatamente após o abate, as meias-carcaças foram identificadas e posteriormente mantidas em câmara fria por 24 horas à temperatura de $2{ }^{\circ} \mathrm{C}$ e, então, foram pesadas. As carcaças foram avaliadas conforme metodologia proposta por Muller (1987) quanto aos pesos e às proporções dos cortes comerciais traseiro serrote, dianteiro e costilhar.

Em cada meia-carcaça, foi medida a espessura de gordura subcutânea (gordura que recobre o músculo longissimus dorsi, entre a $12^{\underline{a}}$ e $13^{\underline{a}}$ costelas), com o auxílio de um paquímetro e a área de olho-de-lombo, medida por um traçado do contorno do músculo longissimus dorsi em papel-vegetal, em corte realizado entre a $12^{\underline{a}}$ e $13^{\underline{a}}$ costelas. O grau de marmoreio foi pontuado de acordo com a distribuição e a quantidade de gordura intramuscular nesta mesma região do músculo longissimus dorsi em: abundante (16 a 18), moderado (13 a 15), médio (10 a 12), pequeno (7 a 9), leve (4 a 6) e traços (1 a 3) (Muller, 1987).

A composição da carcaça foi estimada a partir das equações de Hankins \& Howe (1946), fazendo-se a dissecação da porção que compreende a $9 \underline{a}$, $10^{\underline{a}}$ e $11^{a} \underline{a}$ costelas. A partir desses dados, foram obtidas as porcentagens de osso, músculo e gordura na carcaça: osso: $4,30+0,61 \times\left(x=\%\right.$ de osso separado na $9 \underline{a}, 10^{\underline{a}}$ e $11^{\underline{a}}$ costelas); músculo: $15,56+0,81 \mathrm{x}(\mathrm{x}=\%$ de músculo separado na 9무, $10 \underline{\underline{a}}$ e $11^{\underline{a}}$ costelas); gordura: $3,06+0,82 \mathrm{x}$ ( $\mathrm{x}=\%$ de gordura separada na $9 \stackrel{\mathrm{a}}{ }, 10^{\mathrm{a}}$ e $11^{\underline{a}}$ costelas).

Amostras do músculo longissimus dorsi foram utilizadas para determinar sua composição centesimal em umidade, proteína bruta, gordura e minerais, de acordo com metodologia citada por Silva \& Queiroz (2002), e para medida do $\mathrm{pH}$ e estimativas de perda de água por gotejamento e perdas na cocção, segundo Bridi \& Silva (2006).

Ainda a partir de amostras do músculo longissimus dorsi, sem capa de gordura, foram realizadas análises laboratoriais para determinação da maciez da carne e perfil de ácidos graxos. A maciez da carne dos animais foi determinada pela força de cisalhamento, medida pela lâmina Warner-Bratzler-Shear acoplada a um texturômetro TA-XT2i (Stable Micro Systems), o perfil de ácidos graxos da carne, pela extração dos lipídeos totais, realizada conforme metodologia descrita por Bligh \& Dyer (1959), e o processo de transesterificação, conforme o método 5509 da ISO (1978). Os padrões de ácidos graxos utilizados para identificação do ácido linoleico conjugado (cis-9, trans-11) foi o Sigma Prod. N ${ }^{\circ}$ O5632 e o padrão Supelco Prod. №18919-1AMP, composto de um pool de ésteres metílicos de ácidos graxos de $\mathrm{C}_{4}$ a $\mathrm{C}_{24}$. A determinação foi realizada em cromatógrafo gasoso Shimadzu CG 17-A AF versão 3, sob as seguintes condições: coluna capilar de sílica, marca Supelco-Wax (100 m, 0,25 mm de diâmetro), gás de arraste He em fluxo de 1,2 mL min-1, split (razão de divisão da amostra) de $1 / 100$ e a temperatura do detector foi mantida a $220^{\circ} \mathrm{C}$. A temperatura da coluna foi estabilizada inicialmente a $165^{\circ} \mathrm{C}$ e aquecida gradativamente até $210^{\circ} \mathrm{C}$. O perfil de ácidos graxos foi calculado a partir da somatória das áreas no cromatograma dos respectivos ácidos graxos previamente selecionados e identificados por meio dos padrões empregados, sendo apresentado como porcentagem do total dos ácidos graxos quantificados na amostra.

Os dados obtidos foram submetidos à análise de variância considerando no modelo o efeito de grupo genético e a covariável peso inicial, pelo programa estatístico SAS (1994). As diferenças entre médias foram comparadas pelo teste Tukey a 5\% de probabilidade.

\section{Resultados e Discussão}

Não foram observadas diferenças significativas nos pesos de carcaça fria nem nos pesos e percentuais de cortes comerciais entre os grupos genéticos (Tabela 2). Resultados semelhantes foram encontrados por Costa et al. (2007), que compararam as mesmas características de carcaça de bovinos mestiços Bos taurus e Bos indicus e não notaram influência dos grupos genéticos sobre o rendimento dos cortes básicos, dianteiro, traseiro e costilhar. Esse fato indica, provavelmente, que esses grupos genéticos apresentam taxas de crescimento similares para os cortes estudados, como observado por Souza Junior et al. (2009). 
Apesar da ausência de diferenças no peso de carcaça fria, os animais Bonsmara apresentaram maior área de olhode-lombo e maior porcentagem de músculo em comparação aos dos outros grupos genéticos (Tabela 3). Por outro lado, os animais mestiços e Tabapuã apresentaram maiores porcentagens de gordura na carcaça. Esses resultados diferem dos encontrados por Jorge et al. (2003) em animais dos grupos genéticos Gir, Guzerá, Nelore e Tabapuã, que não diferiram quanto ao crescimento dos tecidos ósseo, muscular e adiposo.

Os animais mestiços B1 (1/2 Bonsmara $+1 / 2$ Nelore) apresentaram maior espessura de gordura de cobertura em comparação aos puros Bonsmara e Tabapuã. Os valores obtidos nos animais B2 ( $1 \frac{1}{2}$ Bonsmara $+1 / 4$ Red Angus + $1 / 4$ Nelore) foram intermediários e não diferiram dos encontrados nos demais grupos. Em todos os grupos genéticos, os animais apresentaram mais que $3 \mathrm{~mm}$ de gordura de cobertura, limite mínimo imposto pela maioria dos frigoríficos para não haver penalização das carcaças. Segundo Luchiari Filho (2000), esse é um valor importante para prevenir o encurtamento das fibras musculares durante a refrigeração das carcaças.

Um fato importante a ser observado é que apesar dos animais terem sido abatidos com o mesmo escore visual de condição corporal (3), isso não significou mesma espessura de gordura de cobertura, confirmando a necessidade de avaliações distintas de acordo com o grupamento genético. De acordo com o que foi observado por Lopes et al. (2008), nos cruzamentos com os genótipos taurinos britânicos, a utilização de até $25 \%$ dos genótipos zebuínos ou taurinos continentais não prejudica o acabamento das carcaças e a espessura de gordura de cobertura e ainda traz inúmeros benefícios que convergem em importantes valores de heterose.

Bianchini et al. (2008) e Pacheco et al. (2010), comparando animais mestiços, também encontraram maiores valores de área de olho-de-lombo para animais taurinos e observaram aumento considerável nesse parâmetro conforme o grau de sangue taurino. Por outro lado, Costa et al. (2007) não observaram diferenças significativas para área de olho-de-lombo de animais puros e mestiços taurinos e zebuínos.

Os valores de marmoreio foram baixos e podem ser classificados, de acordo com Muller (1987), como traços, menor classificação possível, e não diferiram entre os grupos genéticos. Assim como os animais zebuínos, a raça Bonsmara também apresentou carne magra, o que pode ser uma vantagem para a saúde humana. Valores baixos de

Tabela 2 - Cortes da carcaça de bovinos de quatro grupos genéticos terminados em confinamento

\begin{tabular}{|c|c|c|c|c|c|}
\hline \multirow[t]{2}{*}{ Variável } & \multicolumn{4}{|c|}{ Grupo genético } & \multirow[t]{2}{*}{$\operatorname{Pr}>\mathrm{F}$} \\
\hline & B1 & B2 & Bonsmara & Tabapuã & \\
\hline Carcaça fria, kg & $256,7 \pm 2,2$ & $262,2 \pm 2,4$ & $262,2 \pm 2,4$ & $256,5 \pm 2,4$ & 0,0723 \\
\hline Traseiro, kg & $124,0 \pm 1,6$ & $126,9 \pm 1,8$ & $129,5 \pm 1,8$ & $124,4 \pm 1,8$ & 0,1041 \\
\hline Costilhar, kg & $39,0 \pm 1,5$ & $38,3 \pm 1,7$ & $35,9 \pm 1,8$ & $35,1 \pm 1,7$ & 0,5345 \\
\hline Dianteiro, kg & $93,7 \pm 1,8$ & $97,0 \pm 2,0$ & $96,8 \pm 2,0$ & $97,0 \pm 2,0$ & 0,3876 \\
\hline Traseiro, \% & $48,3 \pm 0,5$ & $48,4 \pm 0,6$ & $49,4 \pm 0,6$ & $48,5 \pm 0,6$ & 0,5147 \\
\hline Costilhar, \% & $15,2 \pm 0,6$ & $14,6 \pm 0,6$ & $13,7 \pm 0,6$ & $13,7 \pm 0,6$ & 0,4844 \\
\hline Dianteiro, \% & $36,5 \pm 0,6$ & $37,0 \pm 0,6$ & $36,9 \pm 0,7$ & $37,8 \pm 0,7$ & 0,2622 \\
\hline
\end{tabular}

B1 $=1 / 2$ Bonsmara $+1 / 2$ Nelore, B2 = 1/2 Bonsmara $+1 / 4$ Red Angus $+1 / 4$ Nelore.

Tabela 3 - Características qualitativas e composição tecidual das carcaças de bovinos de quatro grupos genéticos terminados em confinamento ${ }^{1}$

\begin{tabular}{|c|c|c|c|c|c|}
\hline \multirow[t]{2}{*}{ Variável } & \multicolumn{4}{|c|}{ Grupo genético } & \multirow[t]{2}{*}{$\operatorname{Pr}>\mathrm{F}$} \\
\hline & B1 & B2 & Bonsmara & Tabapuã & \\
\hline Área de olho-de-lombo, cm & $67,0 \pm 1,6 c$ & $72,0 \pm 1,7 \mathrm{~b}$ & $83,6 \pm 1,8 a$ & $72,7 \pm 1,8 b$ & 0,0001 \\
\hline Espessura de gordura de cobertura, mm & $8,7 \pm 1,1 \mathrm{a}$ & $7,0 \pm 1,1 \mathrm{ab}$ & $3,8 \pm 1,2 b$ & $4,4 \pm 1,2 b$ & 0,0442 \\
\hline Marmoreio 2 & $3,1 \pm 0,4$ & $2,4 \pm 0,4$ & $1,8 \pm 0,4$ & $1,6 \pm 0,4$ & 0,1119 \\
\hline Músculo (M), \% & $63,4 \pm 0,8 b$ & $62,7 \pm 0,9 b$ & $68,4 \pm 0,9 a$ & $65,1 \pm 0,9 b$ & 0,0062 \\
\hline Gordura (G), \% & $23,9 \pm 0,9 a$ & $23,7 \pm 1,0 \mathrm{a}$ & $17,2 \pm 1,0 b$ & $21,5 \pm 1,0 \mathrm{a}$ & 0,0023 \\
\hline Osso $(\mathrm{O}), \%$ & $13,8 \pm 0,3$ & $14,5 \pm 0,3$ & $15,0 \pm 0,3$ & $14,3 \pm 0,3$ & 0,0795 \\
\hline Relação músculo:osso & $4,6 \pm 0,1$ & $4,3 \pm 0,1$ & $4,6 \pm 0,1$ & $4,6 \pm 0,1$ & 0,3587 \\
\hline Relação músculo+gordura:osso & $6,4 \pm 0,1$ & $6,0 \pm 0,2$ & $5,7 \pm 0,2$ & $6,1 \pm 0,2$ & 0,0727 \\
\hline
\end{tabular}

1 Obtida na seção HH, de acordo com Hankins \& Howe (1946).

${ }^{2}$ Marmoreio = valores variando de $1 \mathrm{a} 18$, sendo 1 a 3 (traços) e de 16 a 18 (abundante).

B1 $=1 / 2$ Bonsmara $1 / 2$ Nelore, B2 = $1 / 2$ Bonsmara $1 / 4$ Red Angus $1 / 4$ Nelore.

a, b, c Médias, na linha, seguidas por letras diferentes diferem $(\mathrm{P}<0,05)$ entre si. 
marmoreio para outros grupamentos genéticos zebuínos também foram observados por Ribeiro et al. (2004; 2008). De acordo com Luchiari Filho (2000), a gordura intramuscular, ou marmoreio, é a última a ser depositada na carcaça e o animal pode ter quantidades consideráveis de gordura interna e subcutânea e não ter quantidade razoável de marmorização.

Um aspecto importante na verificação da qualidade das carcaças é a determinação da relação da porção comestível com quantidade de ossos, vistas pelas proporções músculo:osso e músculo+gordura:osso. Apesar das diferenças observadas para porcentagens de músculo e gordura, não foram encontradas diferenças significativas para porção comestível:osso entre os grupos genéticos.

As porcentagens de umidade, proteína bruta, gordura e minerais no músculo dos animais não apresentaram diferença significativa $(\mathrm{P}>0,05)$ entre os grupos genéticos (Tabela 4). Resultados semelhantes foram obtidos por Pires et al. (2008), que também não encontraram diferenças nos percentuais de umidade, proteína bruta e gordura na carne de animais Bos indicus e mestiços Bos taurus $\times$ Bos indicus, mas notaram diferença apenas no teor de minerais entre os grupos genéticos. Segundo Luchiari Filho (2000), valores normais para a composição química percentual do músculo de um bovino jovem são: 74\% de umidade, 21\% de proteína, $4 \%$ de gordura e $1 \%$ de minerais. Todavia, segundo esse autor, vários fatores influenciam nesta composição, como idade do animal, músculo avaliado e dieta, e a gordura é o componente que mais varia. De maneira geral, o teor de proteína bruta não apresenta grandes variações, embora os valores médios de proteína bruta encontrados neste estudo tenham sido maiores que os encontrados por Ruiz et al. (2005).

Apesar das diferenças nos percentuais de gordura na carcaça e gordura de cobertura dos animais (Tabela 3 ), não houve diferença significativa $(\mathrm{P}>0,05)$ nos percentuais de gordura no músculo longissimus dorsi (Tabela 4) entre os grupos, confirmando os valores de marmoreio observados (Tabela 3). Resultados semelhantes foram obtidos por Rossato et al. (2009), que, em estudos com animais Bos taurus e Bos indicus, não observaram diferenças significativas no teor de gordura no músculo longissimus dorsi.

Os valores para perda de água por gotejamento e perdas na cocção não diferiram $(\mathrm{P}>0,05)$ entre os grupos genéticos, e as médias para perda na cocção foram próximas às observadas por Ribeiro et al. (2004; 2008). Geralmente, quanto maior o teor de gordura na carne, menores as perdas no descongelamento e maiores as perdas por cocção (Luchiari Filho, 2000), e não houve diferença no teor de gordura entre os grupos genéticos.

Não foram observadas diferenças significativas para os valores de $\mathrm{pH}$ entre os grupos genéticos estudados (Tabela 4) e, de acordo com Luchiari Filho (2000), o desejável para carne fresca situa-se em torno de 5,6.

Os melhores resultados de maciez são apresentados pelos grupos genéticos Bonsmara e mestiços B1 (1/2 Bonsmara $+1 / 2$ Nelore) e B2 (1/2 Bonsmara $+1 / 4$ Red Angus + $1 / 4$ Nelore) em relação aos da raça Tabapuã (Tabela 4). Esses resultados estão de acordo com os obtidos por Bianchini et al. (2007), que também verificaram acréscimo à força de cisalhamento com o aumento do grau de sangue zebuíno nos animais experimentais. Outros autores (Heinemann et al., 2003; Pereira et al., 2009) também notaram efeito significativo da utilização de raças taurinas na redução da dureza da carne.

Não foram observadas diferenças $(\mathrm{P}>0,05)$ no total de ácidos graxos saturados entre os grupos genéticos (Tabela 5). Metz et al. (2009) não encontraram efeito da idade de abate dos animais experimentais, mas notaram maior acúmulo percentual de ácido esteárico (C18:0) naqueles com maior grau de sangue zebuíno e relacionaram esse fato à possível bio-hidrogenação ruminal, que poderia ser maior nas raças Bos indicus.

Tabela 4 - Características do músculo longissimus dorsi de bovinos de quatro grupos genéticos terminados em confinamento

\begin{tabular}{|c|c|c|c|c|c|}
\hline \multirow[t]{2}{*}{ Variável } & \multicolumn{4}{|c|}{ Grupo genético } & \multirow[t]{2}{*}{$\operatorname{Pr}>\mathrm{F}$} \\
\hline & B1 & B2 & Bonsmara & Tabapuã & \\
\hline Umidade, \% & $73,5 \pm 1,4$ & $73,7 \pm 1,4$ & $74,1 \pm 1,4$ & $73,9 \pm 1,4$ & 0,8395 \\
\hline Gordura, \% & $1,0 \pm 0,2$ & $0,9 \pm 0,2$ & $0,5 \pm 0,2$ & $0,6 \pm 0,2$ & 0,2722 \\
\hline Minerais, \% & $3,8 \pm 0,1$ & $3,7 \pm 0,1$ & $3,9 \pm 0,1$ & $4,0 \pm 0,1$ & 0,3604 \\
\hline Perda de água por gotejamento, \% & $1,9 \pm 0,3$ & $2,1 \pm 0,3$ & $1,9 \pm 0,3$ & $2,3 \pm 0,4$ & 0,7486 \\
\hline Maciez, kgf & $5,6 \pm 0,5 a$ & $4,9 \pm 0,6 a$ & $4,9 \pm 0,6 a$ & $7,3 \pm 0,6 b$ & 0,0259 \\
\hline
\end{tabular}

B1 = 1/2 Bonsmara + 1/2 Nelore; B2 = 1/2 Bonsmara + 1/4 Red Angus + 1/4 Nelore.

a, b Médias na linha seguidas por letras diferentes diferem $(P<0,05)$ entre si. 
O total de ácidos graxos monoinsaturados, poliinsaturados e insaturados não diferiu $(\mathrm{P}>0,05)$ entre os grupos genéticos (Tabelas 6, 7 e 8). Na carne bovina magra, 54\% dos ácidos graxos são monoinsaturados ou poliinsaturados, que são os recomendados pelos profissionais de saúde (Lichtenstein et al., 2006). Além disso, um terço da gordura saturada da carne bovina é ácido esteárico (C18:0), que tem se mostrado neutro nos efeitos sobre os níveis de colesterol sanguíneo no homem (NCBA, 2007). Neste estudo, o total de ácidos graxos insaturados foi em média $47 \%$ e, para o ácido esteárico, a média foi de 20,7\%, perfazendo aproximadamente 39\% dos ácidos graxos saturados.

Os ácidos graxos palmítico (C16:0), esteárico (C18:0) e oleico (C18:1n-9c) são responsáveis pela maior parte dos ácidos graxos na gordura do músculo longissimus dorsi (Tabelas 5 e 6), estando de acordo com os achados de Ruiz et al. (2005). O ácido oleico (Tabela 6) apresentou valor médio de 40,3\%. Este ácido graxo é benéfico na redução do LDL-colesterol e na elevação do HDL-colesterol no sangue, sendo importante para a saúde humana (Department of Health, 1994).
Atualmente tem se dado bastante importância ao ácido linoleico conjugado (CLA, C18:c9,t11) (Tabela 7), em função principalmente de suas propriedades anticancerígenas e anticarcinogênicas e por ser encontrado unicamente em produtos de origem animal (leite e carne), não sendo produzido no organismo humano (Whigham et al., 2000). Entretanto, os teores deste ácido graxo no músculo foram bastante baixos (Tabela 7).

Segundo o Department of Health (1994), a relação ideal entre os ácidos graxos ômega-6 e ômega-3 ( $\omega$-6: $\omega$-3) é menor que 4:1. Apesar de não haver diferença significativa, o valor encontrado para a carne dos animais B1 está dentro do recomendável e para os animais Bonsmara e B2, estão próximos do ideal (Tabela 8). Mesmo os resultados para o Tabapuã $(11,14)$, estão abaixo da relação média encontrada na dieta ocidental, que é de 17:1 (Garófolo \& Petrilli, 2006). Todavia, segundo esses autores, atualmente recomenda-se relação de 1:1 em dietas mais saudáveis.

A relação entre os ácidos graxos poliinsaturados e saturados foi baixa $(\mathrm{P}>0,05)$ para os quatro grupos genéticos (Tabela 8), pois as médias foram menores que 0,02 . De acordo com Department of Health (1994), a dieta é

Tabela 5 - Perfil de ácidos graxos saturados, em porcentagem do total de gordura, do músculo longissimus dorsi de bovinos de quatro grupos genéticos terminados em confinamento

\begin{tabular}{|c|c|c|c|c|c|}
\hline \multirow[t]{2}{*}{ Ácido graxo } & \multicolumn{4}{|c|}{ Grupo genético } & \multirow[t]{2}{*}{$\mathrm{Pr}>\mathrm{F}$} \\
\hline & B1 & B2 & Bonsmara & Tabapuã & \\
\hline C8:0 & $0,010 \pm 0,003$ & $0,025 \pm 0,003$ & $0,005 \pm 0,003$ & $0,007 \pm 0,003$ & 0,0874 \\
\hline C10:0 & $0,065 \pm 0,007$ & $0,038 \pm 0,007$ & $0,060 \pm 0,007$ & $0,043 \pm 0,008$ & 0,5313 \\
\hline C12:0 & $0,019 \pm 0,004$ & $0,012 \pm 0,004$ & $0,007 \pm 0,004$ & $0,004 \pm 0,004$ & 0,5637 \\
\hline C13:0 & $0,028 \pm 0,012$ & $0,060 \pm 0,012$ & $0,002 \pm 0,012$ & $0,004 \pm 0,013$ & 0,3109 \\
\hline C14:0 & $1,140 \pm 0,245$ & $0,477 \pm 0,245$ & $0,303 \pm 0,245$ & $0,077 \pm 0,252$ & 0,5083 \\
\hline C15:0 & $0,414 \pm 0,155$ & $0,107 \pm 0,155$ & $0,297 \pm 0,155$ & $0,780 \pm 0,200$ & 0,6636 \\
\hline C16:0 & $32,66 \pm 1,35$ & $31,61 \pm 1,35$ & $35,02 \pm 1,35$ & $26,85 \pm 1,51$ & 0,2807 \\
\hline C17:0 & $0,174 \pm 0,022$ & $0,094 \pm 0,022$ & $0,068 \pm 0,022$ & $0,036 \pm 0,025$ & 0,2201 \\
\hline C18:0 & $21,60 \pm 0,92$ & $17,33 \pm 0,92$ & $21,71 \pm 0,92$ & $22,32 \pm 1,02$ & 0,2502 \\
\hline C20:0 & $0,021 \pm 0,014$ & $0,039 \pm 0,014$ & $0,063 \pm 0,014$ & $0,027 \pm 0,015$ & 0,7353 \\
\hline $\mathrm{C} 22: 0$ & $0,004 \pm 0,003$ & $0,002 \pm 0,003$ & $0,014 \pm 0,003$ & $0,011 \pm 0,004$ & 0,5200 \\
\hline Total saturados & $56,13 \pm 1,58$ & $49,80 \pm 1,58$ & $57,55 \pm 1,58$ & $50,16 \pm 1,77$ & 0,2482 \\
\hline
\end{tabular}

B1 = 1/2 Bonsmara $+1 / 2$ Nelore, B2 = 1/2 Bonsmara $+1 / 4$ Red Angus $+1 / 4$ Nelore

Tabela 6 - Perfil de ácidos graxos monoinsaturados, em porcentagem do total de gordura do músculo longissimus dorsi de bovinos de quatro grupos genéticos terminados em confinamento

\begin{tabular}{|c|c|c|c|c|c|}
\hline \multirow[t]{2}{*}{ Ácido graxo } & \multicolumn{4}{|c|}{ Grupo genético } & \multirow[t]{2}{*}{$\operatorname{Pr}>\mathrm{F}$} \\
\hline & B1 & B2 & Bonsmara & Tabapuã & \\
\hline C14:1 & $0,180 \pm 0,040$ & $0,110 \pm 0,040$ & $0,048 \pm 0,040$ & $0,030 \pm 0,045$ & 0,5940 \\
\hline C16:1 & $0,560 \pm 0,085$ & $0,133 \pm 0,085$ & $0,216 \pm 0,085$ & $0,074 \pm 0,095$ & 0,2507 \\
\hline C17:1 & $0,348 \pm 0,063$ & $0,479 \pm 0,063$ & $0,161 \pm 0,063$ & $0,542 \pm 0,071$ & 0,2194 \\
\hline C18:1n-9t & $1,82 \pm 0,08 b$ & $2,49 \pm 0,08 a$ & $1,44 \pm 0,08 b$ & $1,81 \pm 0,09 b$ & 0,0032 \\
\hline C18:1n-9c & $40,30 \pm 1,58$ & $45,96 \pm 1,58$ & $39,52 \pm 1,58$ & $46,40 \pm 1,77$ & 0,3300 \\
\hline C20:1 & $0,128 \pm 0,060$ & $0,178 \pm 0,060$ & $0,301 \pm 0,060$ & $0,120 \pm 0,067$ & 0,6865 \\
\hline Total monoinsaturados & $43,34 \pm 1,60$ & $49,31 \pm 1,60$ & $41,69 \pm 1,60$ & $48,97 \pm 1,78$ & 0,2762 \\
\hline
\end{tabular}

B1 = 1/2 Bonsmara + 1/2 Nelore, B2 = 1/2 Bonsmara + 1/4 Red Angus $+1 / 4$ Nelore

a, b Médias na linha seguidas por letras diferentes diferem $(P<0,05)$ entre si. 
Tabela 7 - Perfil de ácidos graxos poliinsaturados, em porcentagem do total de gordura, do músculo longissimus dorsi de bovinos de quatro grupos genéticos

\begin{tabular}{|c|c|c|c|c|c|}
\hline \multirow[t]{2}{*}{ Ácido graxo } & \multicolumn{4}{|c|}{ Grupo genético } & \multirow[t]{2}{*}{$\operatorname{Pr}>F$} \\
\hline & B1 & B2 & Bonsmara & Tabapuã & \\
\hline C18:2n-6t & $0,127 \pm 0,139$ & $0,623 \pm 0,139$ & $0,278 \pm 0,139$ & $0,377 \pm 0,156$ & 0,6519 \\
\hline C18:2n-6c & $0,230 \pm 0,061$ & $0,070 \pm 0,061$ & $0,260 \pm 0,061$ & $0,309 \pm 0,068$ & 0,5775 \\
\hline C18:3n-6 & $0,053 \pm 0,012$ & $0,077 \pm 0,012$ & $0,064 \pm 0,012$ & $0,085 \pm 0,014$ & 0,8395 \\
\hline C18:3n-3 & $0,029 \pm 0,015$ & $0,073 \pm 0,015$ & $0,022 \pm 0,015$ & $0,010 \pm 0,017$ & 0,5399 \\
\hline C20:2 & $0,003 \pm 0,001$ & $0,002 \pm 0,001$ & $0,006 \pm 0,001$ & $0,006 \pm 0,001$ & 0,1867 \\
\hline$C 20: 3 n-6$ & $0,014 \pm 0,006$ & $0,010 \pm 0,006$ & $0,020 \pm 0,006$ & $0,040 \pm 0,007$ & 0,4455 \\
\hline$C 20: 4 n-6$ & $0,039 \pm 0,006 \mathrm{ab}$ & $0,009 \pm 0,006 b$ & $0,077 \pm 0,006 a$ & $0,026 \pm 0,007 b$ & 0,0142 \\
\hline$C 20: 5 n-3$ & $0,012 \pm 0,002$ & $0,008 \pm 0,002$ & $0,010 \pm 0,002$ & $0,009 \pm 0,003$ & 0,7525 \\
\hline$C 22: 6 n-3$ & $0,003 \pm 0,001$ & $0,001 \pm 0,001$ & $0,008 \pm 0,001$ & $0,001 \pm 0,001$ & 0,1201 \\
\hline C18:c9,t11 & $0,021 \pm 0,003$ & $0,016 \pm 0,003$ & $0,023 \pm 0,003$ & $0,015 \pm 0,004$ & 0,7108 \\
\hline Total poliinsaturados & $0,532 \pm 0,125$ & $0,889 \pm 0,125$ & $0,768 \pm 0,125$ & $0,876 \pm 0,143$ & 0,7545 \\
\hline
\end{tabular}

B1 $=1 / 2$ Bonsmara $+1 / 2$ Nelore, $B 2=1 / 2$ Bonsmara $+1 / 4$ Red Angus $+1 / 4$ Nelore.

a, b Médias na linha seguidas por letras diferentes diferem $(\mathrm{P}<0,05)$ entre si.

Tabela 8 - Relações entre grupos de ácidos graxos do músculo longissimus dorsi de bovinos de quatro grupos genéticos

\begin{tabular}{lcccr}
\hline Ácido graxo & \multicolumn{2}{c}{ Grupo genético } & Pr $>$ F \\
\cline { 2 - 5 } & B1 & B2 & Bonsmara & Tabapuã \\
\hline Ômega-6 $(\omega-6)$ & $0,107 \pm 0,012$ & $0,096 \pm 0,012$ & $0,162 \pm 0,012$ & $0,150 \pm 0,014$ \\
Ômega-3 $(\omega-3)$ & $0,044 \pm 0,015$ & $0,082 \pm 0,015$ & $0,039 \pm 0,015$ & 0,2250 \\
$\omega$-6: $\omega$-3 & $2,52 \pm 1,04$ & $5,56 \pm 1,04$ & $4,43 \pm 1,04$ & $0,020 \pm 0,017$ \\
Insaturados & $43,87 \pm 3,16$ & $50,20 \pm 3,16$ & $42,45 \pm 3,16$ & 0,5897 \\
Poliinsaturados:saturados & $0,010 \pm 0,002$ & $0,018 \pm 0,002$ & $0,013 \pm 0,002$ & 0,0817 \\
Monoinsaturados:saturados & $0,819 \pm 0,055$ & $1,020 \pm 0,055$ & $0,731 \pm 0,055$ & $0,017 \pm 0,003$ \\
Insaturados:saturados & $0,829 \pm 0,055$ & $1,037 \pm 0,055$ & $0,745 \pm 0,055$ & $0,992 \pm 0,062$ \\
\hline
\end{tabular}

B1 $=1 / 2$ Bonsmara $+1 / 2$ Nelore, B2 $=1 / 2$ Bonsmara $+1 / 4$ Red Angus $+1 / 4$ Nelore.

considerada pouco saudável se a relação for inferior a 0,4 . A relação de ácidos graxos insaturados:saturados não diferiu entre os grupos genéticos (Tabela 8). Metz et al. (2009) observaram que a relação ácidos graxos insaturados:saturados é maior em animais com predominância taurina em relação aos zebuínos.

A ausência de diferenças estatísticas entre os grupos genéticos para a quase totalidade dos ácidos graxos corrobora os achados de Pires et al. (2008), que também não notaram diferenças entre quatro grupos genéticos (Nelore e meio-sangue Nelore $\times$ Canchim, Nelore $\times$ Limousin e Aberdeen Angus $\times$ Nelore) e comentaram que um dos principais fatores a afetar a composição lipídica da carne é a alimentação.

\section{Conclusões}

Animais da raça Bonsmara podem ser utilizados na produção de bovinos para corte por apresentarem boa produção de carcaça e carnes com qualidade. Animais com maior porcentagem de sangue zebuíno apresentam carnes mais duras. O grupo genético não afeta a distribuição dos cortes na carcaça nem o perfil de ácidos graxos.

\section{Agradecimentos}

Ao Conselho Nacional de Pesquisa e Desenvolvimento (CNPq), pelas bolsas de produtividade em pesquisa para Ribeiro e Mizubuti.

\section{Referências}

ALVES, D.D.; TONISSI, R.H.; GOES, B. Maciez da carne bovina. Ciência Animal Brasileira, v.6, n.3, p.135-149, 2005.

BIANCHINI, W.; SILVEIRA, A.C.; JORGE, A.M. et al. Efeito do grupo genético sobre as características de carcaça e maciez da carne fresca e maturada de bovinos superprecoces. Revista Brasileira de Zootecnia, v.36, n.6, p.2109-2117, 2007.

BIANCHINI, W.; SILVEIRA, A.C.; ARRIGONI, M.B. et al. Crescimento e características de carcaça de bovinos superprecoces Nelore e Simental e mestiços. Revista Brasileira de Saúde e Produção Animal, v.9, n.3, p.554-564, 2008.

BLIGH, E.G.; DYER, W.J. A rapid method of total lipid extraction and purification. Canadian Journal Biochemistry Physiology, v.37, p.911-917, 1959.

BRIDI, A.M.; SILVA, C.A. Métodos de avaliação da carcaça e da carne suína. Londrina: Midiograf, 2006. 97p.

COSTA, D.; ABREU, J.B.R.; MOURÃO, R.C. et al. Características de carcaça de novilhos inteiros Nelore e F1 Nelore x Holandês. Ciência Animal Brasileira, v.8, n.4, p.687-696, 2007.

CURI, R.A.; CHARDULO, L.A.L.; MASON, M.C. et al. Effect of single nucleotide polymorphisms of CAPN1 and CAST genes on meat traits in Nellore beef cattle (Bos indicus) and in their crosses with Bos taurus. Animal Genetics, v.40, p.456-462, 2009. 
DEPARTMENT OF HEALTH. Nutritional aspects of cardiovascular disease. London: HMSO, 1994. 178p.

FARIA, C.U.; MAGNABOSCO, C.U.; ALBUQUERQUE, L.G. et al. Estimativas de correlações genéticas entre escores visuais e características de carcaça medidas por ultrassonografia em bovinos Nelore utilizando modelos bayesianos linear-limiar. Revista Brasileira de Zootecnia, v.38, n.11, p.2144-2151, 2009.

GARÓFOLO, A.; PETRILLI, A.S. Balanço entre ácidos graxos ômega-3 e 6 na resposta inflamatória em pacientes com câncer e caquexia. Revista de Nutrição, v.19, n,5, p.611-621, 2006.

HADLICH, J.C.; LONGHINI, L.G.R.; MASON, M.C. [2008]. A influência do colágeno na textura da carne. Pubvet, v.2, n.32, 2008. Disponível em: <http://www.pubvet.com.br/ artigos_imp.asp?artigo=160> Acesso em: 9 jul. 2009

HANKINS, O.G.; HOWE, P.E. Estimation of the composition of beef carcasses and cuts. Washington: USDA, 1946. 20p. (Technical Bulletin, 926).

HEINEMANN, R.J.B.; PINTO, M.F.; ROMANELLI, P.F. Fatores que influenciam a textura da carne de novilhos Nelore e cruzados Limousin-Nelore. Pesquisa Agropecuária Brasileira, v.38, n.8, p.939-971, 2003.

INTERNATIONAL ORGANIZATION FOR STANDARDIZATION ISO. Animal and vegetable fats and oils preparation of methyl esters of fatty acids. Method ISO 5509, Geneve, p.1-6, 1978.

JORGE, A.M.; FONTES, C.A.A.; CERVIERI, R.C. Crescimento relativo e composição do ganho de tecidos da carcaça de zebuínos de quatro raças. Revista Brasileira de Zootecnia, v.32, n.4, p.986-991, 2003.

LICHTENSTEIN, A.H.; APPEL, L.J.; BRANDS, M. et al. Diet and lifestyle recommendations revision. A scientific statement from the American Heart Association Nutrition Committee. Dallas, 2006. p.82-96. (Circulation 114).

LOPES, J.S.; RORATO, P.R.N.; WEBER, T. et al. Metanálise para características de carcaça de bovinos de diferentes grupos genéticos. Ciência Rural, v.38, n.8, p.2278-2284, 2008.

LUCHIARI FILHO, A. Pecuaria da carne bovina. São Paulo: A. Luchiari Filho, 2000. 134p.

MACHADO, R.; CORRÊA, R.F.; BARBOSA, R.T. et al. Escore da condição corporal e sua aplicação no manejo reprodutivo de ruminantes. São Carlos: EMBRAPA, 2008. 16f (Circular Técnica, 57).

McDOWELL, L.R.; CONRAD, J.H.; THOMAS, J.E. et al. Tabelas de composição de alimentos da América Latina. Gainesville: Universidade da Flórida, 1974. 47p.

METZ, P.A.M.; MENEZES, L.F.G.; SANTOS, A.P. et al. Perfil de ácidos graxos na carne de novilhos de diferentes idades e grupos genéticos terminados em confinamento. Revista Brasileira de Zootecnia, v.38, n.3, p.523-531, 2009.
MÜLLER, L. Normas para avaliação de carcaças e concurso de carcaças de novilhos. 2.ed. Santa Maria: Universidade Federal de Santa Maria, 1987. 31p.

NATIONAL CATTLEMEN'S BEEF ASSOCIATION - NCBA. [2007]. Beef facts: stearic acid - a unique saturated fat. Centennial: National Cattlemen's Beef Association. Disponível em: <http://www.beefnutrition.org/CMDocs/BeefNutrition/ StearicAcid.pdf $>$ Acesso em: 9 jul. 2009

PACHECO, P.S.; RESTLE, J.; BRONDANI, I.L. et al. Grupo genético, sistema de acasalamento e efeitos genéticos aditivos e não-aditivos nas características de musculosidade da carcaça de novilhos oriundos do cruzamento rotativo Crarolês x Nelore. Revista Brasileira de Zootecnia, v.39, n.3, p.494-502, 2010.

PARMIGIANI, P.; TORRES, R. Para além da rastreabilidade. Revista Nacional da Carne, v.33, n.391, p.8-15, 2009.

PEREIRA, P.M.R.C.; PINTO, M.F.; ABREU, U.G.B. et al. Características de carcaça e qualidade de carne de novilhos superprecoces de três grupos genéticos. Pesquisa Agropecuária Brasileira, v.44, n.11, p.1520-1527, 2009.

PIRES, I.S.; ROSADO, G.P.; COSTA, N.M.B. et al. Composição centesimal e perfil de ácidos graxos da carne de novilho precoce alimentado com lipídios protegidos. Ciência e Tecnologia de Alimentos, v.28, p.178-183, 2008.

RIBEIRO, E.L.A.; HERNANDEZ, J.A.; ZANELLA, E.L. et al. Growth and carcass characteristics of pasture fed LHRH immunocastrated, castrated and intact Bos indicus bulls. Meat Science, v.68, n.2, p.285-290, 2004.

RIBEIRO, E.L.A.; HERNANDEZ, J.A.; ZANELLA, E.L. et al. Desempenho e características de carcaça de bovinos de diferentes grupos genéticos. Revista Brasileira de Zootecnia, v.37, n.9, p.1669-1673, 2008.

ROSSATO, L.V.; BRESSAN; M.C.; RODRIGUES, E.C. et al Composição lipídica de carne bovina de grupos genéticos taurinos e zebuínos terminados em confinamento. Revista Brasileira de Zootecnia, v.38, n.9, p.1841-1846, 2009.

RUIZ, M.R.; MATSUSHITA, M.; VISENTAINER, J.V. et al. Proximate chemical composition and fatty acid profiles of Longissimus thoracis from pasture fed LHRH immunocastrated, castrated and intact Bos indicus bulls. South African Journal of Animal Science, v.35, n.1, p.13-18, 2005.

SILVA, D.J.; QUEIROZ, A.C. Análise de alimentos: métodos químicos e biológicos. Viçosa, MG: UFV, 2002. 235p.

SOUZA JUNIOR, A.A.O.; SANTOS, C.L.; CARNEIRO, P.L.S. et al. Estudo alométrico dos cortes da carcaça de cordeiros cruzados Dorper com as raças Rabo Largo e Santa Inês. Revista Brasileira de Saúde e Produção Animal, v.10, n.2, p.423-433, 2009.

STATISTICAL ANALYSIS SYSTEM - SAS. SAS/STAT User's guide. Cary: SAS Institute Inc., 1994. v.2. 846p.

WHIGHAM, L.D.; COOK, M.E.; ATKINSON, R.L. Conjugated linoleic acid: implications for human health. Pharmacological Research, v.42, n.6, p.503-510, 2000. 